\title{
New Technologies in Health Education and Research
}

\author{
Juan A. Juanes \\ University of Salamanca, \\ VisualMed System Research Group \\ Spain \\ jajm@usal.es
}

\author{
Pablo Ruisoto \\ University of Salamanca, \\ VisualMed System Research Group \\ Spain \\ ruisoto@usal.es
}

\author{
Piedade A. Barros \\ Polytechnic Institute of Porto, \\ Portugal \\ pgb@estsp.ipp.pt
}

\begin{abstract}
The studies in this track provided an updated overview of different technological innovation procedures in distinct health science fields. Thus, technological applications from medical imaging treatment and three-dimensional visualization to simulation systems useful in clinical practice training (simulations with mannequins, training with manual control devices, virtual reality techniques with stereo vision helmets, amongst others) are presented. The main objective of these procedures is to improve the quality of university teaching and continuing education, using the latest resources, which are starting to be implemented in different universities.
\end{abstract}

\section{Categories and Subject Descriptors}

H.1.2. [User/Machine Systems]: Human information processing

\section{General Terms}

Experimentation, Human Factors

\section{Keywords}

New technology; health; education; research

Permission to make digital or hard copies of all or part of this work for personal or classroom use is granted without fee provided that copies are not made or distributed for profit or commercial advantage and that copies bear this notice and the full citation on the first page. To copy otherwise, or republish, to post on servers or to redistribute to lists, requires prior specific permission and/or a fee. TEEM '15, October 07 - 09, 2015, Porto, Portugal Copyright is held by the owner/author(s). Publication rights licensed to ACM. ACM 978-1-4503-3442-6/15/10...\$15.00

DOI: http://dx.doi.org/10.1145/2808580.2808581

\section{NEW TECHNOLOGIES IN HEALTH EDUCATION AND RESEARCH}

This track presents a general overview of innovative teaching methods (clinical simulation, medical imaging treatment and manipulation software, applications of mobile devices (smartphones and tablets) in medical training, advanced visualization systems with virtual reality techniques using helmets, etc.), applied in health science training through the experience of different research groups.

It is indisputable that technological development, especially information technology in health science provides evident benefits both in training and clinical practice. The technological revolution has led to the constant creation of new devices and resources that facilitate learning. In recent years, technological material for clinical training as well as several interactive computer procedures of great teaching value have been made, which enable excellent clinical simulation teaching material to users for training in different health science fields. The spectrum of medical simulation ranges from simple replicas of the human body (bones, anatomical parts, etc.) or the creation of operating rooms or medical consultation rooms; to high fidelity patient simulators, such as high definition mannequins connected to a computer to program different proceedings when there is a clinical case. All these systems have been developed to resemble clinical environments with high validity.

These technological resources allow its users to acquire the necessary skills and experience to have the appropriate knowledge in daily clinical practice.

Therefore, it seems evident that the use of information technology environments in medical training, as additional teaching resources, facilitate and optimize learning and clinical 
skills in students and residents of different health science specialties.

These technological resources should be used to encourage independent or group learning experiences and become an important stimulus and additional support for its different users, making the teaching and learning process more practical and attractive through complementary technology tools that enhance and provide a significant improvement in learning and acquiring knowledge.

Nowadays, the use of different information technology commercial developments enable the creation of threedimensional medical images that certainly improve the identification of anatomical structures, generated from the segmentation of Magnetic Resonance (MR) and Computerized Tomography (CT) seriated sections. Thus, software like Osirix ${ }^{\circledR}$, Amira ${ }^{\circledR}$ and Analyze ${ }^{\circledR}$, 3D Slicer ${ }^{\circledR}$, amongst many others, allow the generation of these types of three-dimensional images, having a better understanding of anatomical and radiological body structures, facilitating their study and comprehension.

The accelerated transformations in society, as a result of technological developments, are certainly producing a great impact on the methods and models used in university teaching. The use of visual resources like stereo vision helmets is one of the most attractive and innovative methods in student training as well as being reusable and useful tools to encourage and motivate student learning in any discipline within health science. The different interactive visual systems in medical training provide an incentive for the student, in addition to improving long-term retention.

Immersive technology applications, using virtual reality headsets aimed to acquire clinical skills, provide important advantages for learning and clinical training, as a rehearsal prior to real life situations the student will face. The stereoscopic helmets are completely immersive, to the extent of fully nullifying the real environment's view and substituting it for the virtual one.

Virtual Reality (VR) techniques are being used more frequently in several applications within medical training. The VR is a computer system that creates an artificial world in which the user has the feeling of being inside with the ability of navigating through it and manipulating its objects. By using this special visualization system, the user has a direct view as a result, where computer generated images are also presented.

In recent years it is clear that we have seen a constant development of new technologies and their applications in teaching, to overcome the limitations of traditional methods and facilitate involvement and interaction of students with the learning content, thus improving their education.

The studies presented in this track include a sample of the current efforts being made to integrate new technologies in research and practice within health education.

The first group of studies focus on the development of medical applications in three contexts: mobile devices, defining a quality protocol ("Synopsis of discussion session on defining a new quality protocol for medical apps"), application of software aimed at medical image processing to improve the study of the brain's ventricular system ("Technologic 3D view design of the anatomical structures with teaching purpose", "Application of the 3D Slicer software in the Study of the Brain's Ventricular System") and a practical comparison of two of the main free open source "point and click" software packages for building and running experiments in Psychology and Neuroscience: PsychoPy and OpenSesam ("Graphical Experiment Builder Applications for Neuroscientists”).

The second group of studies focus on the application of simulation resources to acquire or train medical skills, such as surgical intervention in brain injury ("Practical Applications of Movement Control Technology in the Acquisition of Clinical Skills") or virtual reality to visualize a hospital operating room through stereoscopic rendering, using the Oculus Rift headset with a wide field of vision ("Analysis of the Oculus Rift Device as a Technological Resource in Medical Training through Clinical Practice").

Finally, a third group of articles address new issues that have still not received enough attention from the scientific literature in other contexts, but are certainly attracting a growing interest ("A theoretical inquiry into the role of enaction in Cybertherapy"; "E-Health Literacy in Ageing"). One of these articles demonstrates how the cooperative networking of students increases engagement and academic outcomes ("Cooperative Networks and their Influence on Engagement with Nursing Students”).

\section{REFERENCES}

[1] Juanes, J.A. 2011. Nuevos entornos tecnológicos para la simulación en educación médica. Educación Médica, 14 (2), 18-20.

[2] Méndez, J.A., Velasco, M.A., Cabrero, F.J., Sánchez, J.M., Conde, M.J. 201. Recursos tecnológicos audiovisuales de formación en red: sistemas streaming media y teleinmersivos,. In Juanes Méndez, J. A. (Coord.) Avances tecnológicos digitales en metodologías de innovación docente en el campo de las Ciencias de la Salud en España. Revista Teoría de la Educación: Educación y Cultura en la Sociedad de la Información. 11(2). Universidad de Salamanca, pp. 214-231.

[3] Juanes, J.A., Ruisoto, P., Prats, A., Gómez, J.J. 2013. Advance technology for enhanced study of the brain from neuroimaging. Published by International Association of Technology, Education and Development (IATED). pp: 5073-5082.

[4] Juanes, J.A., Ruisoto, P., Prats, A., Gómez, J.J. 2012. Three-dimensional visualization for the advance study of functional neuroimages in schizophrenia. In Gómez Chova, A. López Martínez, I. Candel Torres. (Eds). International Association of Technology, Education and Development. IATED. pp: 3542-3550.

[5] Juanes, J.A., Prats, A., Álvarez, H. Rodríguez, M.J. 2012. Digital erasing techniques to create virtual learning sets. VII: The university, an institution of society ACUP (Associació Catalana d'Universitats Públiques). Barcelona.

[6] Ruisoto, P., Juanes, J.A., Mayoral, P., Prats, A. 2012. Applied Medical Informatics for Neuroanatomy Training. In Proceedings from XIV International Symposium on Computers in Education, pp. 37-41. Andorra: Publicaciones La Salle. 29-31 October. 
[7] Ruisoto, P., y Juanes, J.A. 2012. Aportación de la reconstrucción y visualizacion tridimensional de estructuras anatómicas en contextos docentes de aprendizaje. En: Ensino Superior: Inovação e qualidade na docência. Edita: CIIE - Centro de Investigação e Intervenção Educativas. pp: $2638-2650$

[8] Ruisoto, P., Juanes, J.A., Prats, A. 2012. Entorno virtual de aprendizaje mediante procedimientos tecnológicos informáticos. Ejemplo de aplicación en Neuroanatomía. En: Ensino Superior: Inovação e qualidade na docência. Edita: CIIE - Centro de Investigação e Intervenção Educativas. pp: 2851-2661.

[9] Ruisoto, P., Juanes, J.A., Contador, I., Mayoral, P., Prats, P. 2012. Experimental Evidence for Improved Neuroimaging Interpretation Using Three-Dimensional Graphic Models. Anat Sci Ed. 5, 132-137 doi: 10.1002/ase.1275. 2012.

[10] Ruisoto P., Juanes Méndez JA, Prats Galino A, Mayoral Babiano P, Gómez Borrallo JJ. (2011). Effectiveness of 3D digital visualization in neuroanatomy. An empirical study. Publishep by IATED. Barcelona, Spain. pp 2264-2270. Spain.

[11] Briz Ponce, L., Juanes Méndez, J. A., \& García-Peñalvo, F. J. (2015). Dispositivos móviles y apps: Características y uso actual en educación médica. Novática. Revista de la Asociación de Técnicos en Informática, 231, 86-91

[12] Sánchez, A., Juanes, J.A., Hernández, F., Curto, B., Moreno Rodilla, V. y Alonso, P. (2015). Papel de las nuevas tecnologías en el aprendizaje o mejora de habilidades clínicas en Anestesiología y Reanimación. Nuevo hospital, 11(1), 3-10.

[13] Prats, A., Reina, M.A., Mavar, M., Puigdellivol-Sánchez A., Juanes, J.A., De Andrés, J.A. 2015. 3D Interactive Model of Lumbar Spinal Structures of Anesthetic Interest. Clinical Anatomy, 28: 205-212

[14] Nieto, J., Juanes, J.A., Alonso, P., Curto, B., Hernández, F., y Moreno, V. 2014. Simulador ecográfico: utilidad como herramienta de formación para la infiltración de toxina botulínica ecoguiada. Revista Cientifica Vozes dos Vales 6,

[15] Juanes, J.A., Ruisoto, P., Prats, A., Framiñán, A., and Riesco, J.M. 2014. Computerised Anatomical Modelling of the Optic Pathway and Oculomotor System from Magnetic Resonance. Journal of Neuroradiology, 3(41): 168-176.

[16] Juanes, J.A., Ruisoto, P. Velasco, M.A., Gómez, J.J. 2013. Technological innovation in cerebrovascular accident primary heath care. International Association of Technology, Education and Development (IATED), pp: 5087-5093. 